\title{
GOLPH3 and YB-1 Are Novel Markers Correlating With Poor Prognosis in Prostate Cancer
}

\author{
Nehad M. R. Abd El-Maqsoud ${ }^{a}$,, Nisreen A. A. Osman ${ }^{\text {a }}$, Amr M. A. El-Hamid ${ }^{\text {a }}$ \\ Tarek K. Fath El-Bab ${ }^{\mathrm{a}}$, Ehab M. Galal ${ }^{\mathrm{a}}$
}

\begin{abstract}
Background: Prostate cancer is a common and aggressive cancer among men. Despite advances in the treatment, the mechanisms involved in progression are still unclear. New prognostic markers should be explored for better design of patient-specific therapeutic regimens.
\end{abstract}

Methods: This study was performed on 120 patients stratified as 76 with prostatic carcinoma, 12 with low-grade prostate intraepithelial lesion, 12 with high-grade prostate intraepithelial lesion and 20 with benign prostate hyperplasia. Immunohistochemical study was done for Golgi phosphoprotein 3 (GOLPH3) and Y-box binding protein-1 (YB-1) analysis. Correlation with clinicopathological data and overall survival was analyzed.

Results: Both GOLPH3 and YB-1 showed increased expression from benign to malignant tumors. In prostatic carcinoma, cytoplasmic GOLPH3 was associated with Gleason score, stage and androgen receptor $(\mathrm{P}=0.034, \mathrm{P}<0.001$, and $\mathrm{P}=0.008$ respectively). Nuclear YB-1 expression was associated with Gleason score and androgen receptor ( $\mathrm{P}=0.018$ and $\mathrm{P}=0.024$ respectively). Cytoplasmic YB-1 expression was associated with Gleason score, stage and androgen receptor $(\mathrm{P}=0.008, \mathrm{P}=0.027$, and $\mathrm{P}<0.001$ respectively). High Gleason score $(\mathrm{P}=0.004)$, high stage $(\mathrm{P}<0.001)$ and androgen receptor $(\mathrm{P}=0.006)$ were the only detected adverse prognostic clinicopathological factors. Moderate/intense GOLPH3 and high nuclear and cytoplasmic YB-1 expression were correlated with shorter overall survival ( $\mathrm{P}<0.001, \mathrm{P}=0.020$, and $\mathrm{P}<0.001$ respectively). In the multivariate analysis, moderate/intense GOLPH3 expression was the only predictor of overall survival $(\mathrm{P}=0.025)$.

Conclusions: High GOLPH3 and nuclear/cytoplasmic YB-1 expression correlated with poor prognosis in prostate cancer. Both markers can be promising targets for new treatment strategies.

Manuscript accepted for publication December 14, 2015

${ }^{\text {aF }}$ aculty of Medicine, Minia University, Egypt

${ }^{b}$ Corresponding Author: Nehad M. R. Abd El-Maqsoud, Department of Pathology, Faculty of Medicine, Minia University, Egypt.

Email: nehadreda@ymail.com

doi: http://dx.doi.org/10.14740/wjon952w
Keywords: GOLPH3; YB-1; Prostate cancer; Immunohistochemistry

\section{Introduction}

Prostate cancer (PC) is the second most common malignancy among men in Europe and America [1]. In Egypt, it ranks the sixth $(4.27 \%)$ and the incidence increases with aging [2]. PC is an aggressive disease and many patients die of metastatic cancer [3]. Despite advances in the treatment of PC, the mechanisms involved in progression and recurrence are still unclear. New prognostic markers should be explored for better design of patient-specific therapeutic regimens.

The specific diagnosis of prostatic intraepithelial neoplasia (PIN) has been a matter of debate considering its clinical significance and relationship to PC. PIN was simply classified into low-grade PIN (LGPIN) and high-grade PIN (HGPIN) [4]. LGPIN is associated with about $16 \%$ risk of developing PC; HGPIN carries about $21 \%$ risk that is close to the risk following the diagnosis of benign prostate hyperplasia (BPH) which is $20 \%$ [5].

The prostate gland development depends mainly on androgen through binding its androgen receptor (AR). Moreover, $\mathrm{AR}$ is important in the progression of PC being expressed in most of androgen-independent or hormone refractory PC. AR has a role in the deregulation of several oncogenes and tumor suppressor genes. So, its mutation may lead to the failure of endocrine therapy of PC [6].

Golgi phosphoprotein 3 (GOLPH3), also known as GPP34, GMx33, or MIDAS, is a membrane protein with a molecular weight of $34 \mathrm{kDa}$ that plays a role in anterograde and retrograde Golgi trafficking and interactions with the cytoskeleton to maintain Golgi structure [7]. It is a promising marker in cell biology. Previous studies showed the presence of GOLPH3 as an oncogene encoded by a gene on chromosome $5 \mathrm{p} 13$ in several human cancers including breast, oral tongue, prostate, kidney and liver cancers [8-13]. In addition, the overexpression of GOLPH3 has been indicated to be correlated with clinically aggressive behavior of cancers and the prognosis of patients [13-15].

GOLPH3 promotes cell transformation and tumor growth by activating mammalian target of rapamycin (mTOR-YB-1) signaling pathway. Tumor cells overexpressing GOLPH3 are 
more sensitive to rapamycin $[8,15]$. However, how GOLPH3 regulates cell migration and invasion is largely unknown.

Mammalian Y-box binding protein-1 (YB-1) is a member of the DNA/RNA-binding family of proteins that are involved in DNA repair, mRNA transcription, splicing, translation and stabilization [16]. YB-1 is related to cell proliferation, anti-apoptosis, and epithelial-mesenchymal transition as well as castration resistance in $\mathrm{PC}$ [17]. It is reported that YB-1 translocation from the cytoplasm to the nucleus stimulates transcription of a number of genes encoding proteins responsible for drug resistance, disease recurrence, metastasis and poor prognosis in various cancers $[18,19]$. YB-1 acts as a biomarker for predicting the efficacy of high-dose chemotherapy in breast cancer [20]. Increases in YB-1 protein expression have also been described for other malignant tumors, such as osteosarcoma, PC, pancreatic adenocarcinoma, colorectal carcinoma, and glioblastoma, indicating the clinical impact of YB-1 for the progression of these malignant diseases $[15,18]$.

Little is known about correlation between GOLPH3 and YB-1 expression and prognosis in patients with PC. In the present study, we investigated the expression of GOLPH3, YB-1 in PC compared to its expression in BPH and PIN. Their correlation with clinicopathological features and their prognostic value for patients' survival was also studied.

\section{Materials and Methods}

\section{Patients' data}

This study was performed on 120 patients in the period extending from 2009 to 2014; these patients had undergone prostatectomy, transrectal prostate biopsy under ultrasound guidance, or transurethral resection of the prostate. Seventy-six (63.3\%) patients suffered from PC, 12 (10\%) cases were diagnosed with HGPIN and $12(10 \%)$ with LGPIN. Twenty (16.7\%) patients were diagnosed with BPH. All the specimens were fixed with $4 \%$ buffered formalin and embedded in paraffin. All the slides were blindly reviewed by two pathologists, and a final diagnosis was reached.

Clinical data, including Gleason score (GS), baseline prostate-specific antigen (PSA), stage and follow-up status, were retrospectively obtained from patients' files at Minia University Hospital and Minia Oncology Center, Egypt. The data analysis was approved by our hospital review board.

\section{Immunohistochemical procedure}

Slides were deparaffinized in xylene, rinsed with phosphatebuffered saline (PBS), and subjected to epitope retrieval treatment in $0.01 \mathrm{M}$ citrate buffer solution ( $\mathrm{pH}$ 6.0) for 2 min by a microwave. The sections were cooled at room temperature and further rinsed with PBS three times for 5 min each. The sections were then incubated with $0.3 \%$ hydrogen peroxide at room temperature for $10 \mathrm{~min}$ to quench the endogenous peroxidase activity and rinsed three more times for 5 min each. Sections were subsequently incubated with the anti-androgen
Table 1. Patients' Clinicopathological Parameters in Patients With PC ( $\mathrm{N}=76)$

\begin{tabular}{|c|c|c|}
\hline Clinicopathological parameters & $\mathbf{N}$ & $\%$ \\
\hline \multicolumn{3}{|l|}{ Age (years) } \\
\hline$\leq 60$ & 8 & 10.5 \\
\hline$>60$ & 68 & 89.5 \\
\hline \multicolumn{3}{|l|}{ Baseline PSA (ng/mL) } \\
\hline$<10$ & 13 & 17.1 \\
\hline $10-20$ & 39 & 51.3 \\
\hline$>20$ & 24 & 31.6 \\
\hline \multicolumn{3}{|l|}{ Gleason score } \\
\hline Gleason 2 - 6 & 17 & 22.4 \\
\hline Gleason 7 & 38 & 50 \\
\hline Gleason 8 - 10 & 21 & 27.8 \\
\hline \multicolumn{3}{|l|}{$\mathrm{pT}$ status } \\
\hline $\mathrm{T} 2$ & 40 & 52.6 \\
\hline $\mathrm{T} 3$ & 27 & 35.5 \\
\hline $\mathrm{T} 4$ & 9 & 11.8 \\
\hline \multicolumn{3}{|l|}{ Perineural invasion } \\
\hline Absent & 34 & 44.7 \\
\hline Present & 42 & 55.3 \\
\hline \multicolumn{3}{|l|}{ pN status } \\
\hline No & 61 & 80.3 \\
\hline N1 & 15 & 19.7 \\
\hline \multicolumn{3}{|l|}{ Stage } \\
\hline $\mathrm{I}$ & 5 & 6.6 \\
\hline IIA & 18 & 23.7 \\
\hline IIB & 14 & 18.4 \\
\hline III & 21 & 27.6 \\
\hline IV & 18 & 23.7 \\
\hline \multicolumn{3}{|l|}{ Mortality } \\
\hline Alive & 30 & 39.5 \\
\hline Dead & 46 & 60.5 \\
\hline
\end{tabular}

pT status: pathological tumor stage; pN: lymph node status.

receptor antibody (Abcam, rabbit polyclonal, 1:500), antiGOLPH3 primary antibody (Abcam, ab113649; rabbit polyclonal; 1:100 dilutions) and anti-YB-1 antibody (Abcam, ab12148; rabbit polyclonal; 1:500), overnight at $4{ }^{\circ} \mathrm{C}$. Then sections were washed with PBS and incubated with biotinylated secondary antibody for $30 \mathrm{~min}$ at room temperature. Streptavidin was applied for $30 \mathrm{~min}$ at room temperature. The color reaction was performed using diaminobenzidine (DAB) solution for $5 \mathrm{~min}$. Finally, the slides were washed, counterstained with Mayer's hematoxylin, dehydrated, and mounted. A section of PC, breast carcinoma and human duodenum were used as a positive control for AR, GOLPH3 and YB-1 proteins respectively. 


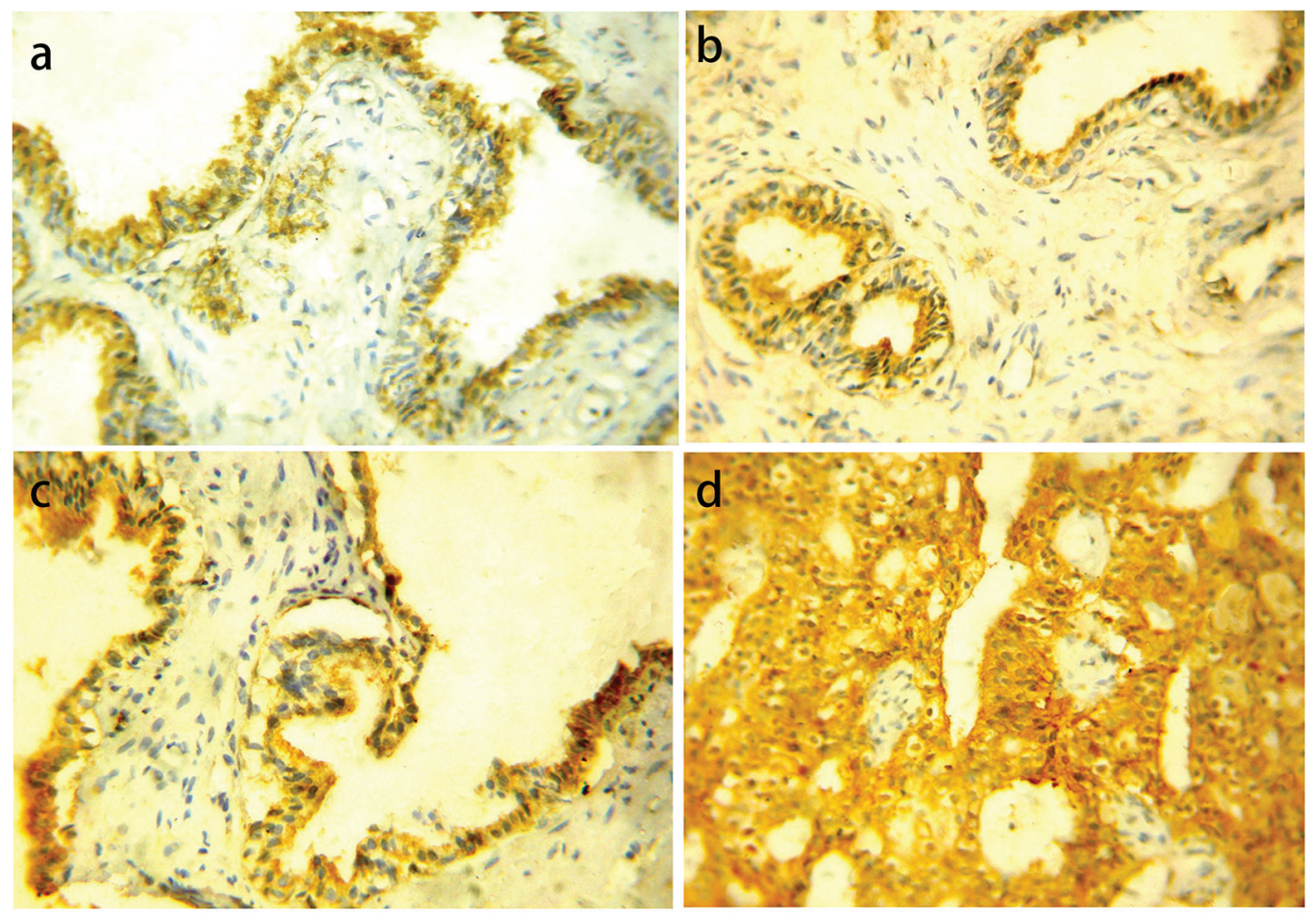

Figure 1. GOLPH3 protein cytoplasmic expression in different prostatic lesions using IHC. (a) GOLPH3 protein showed positive expression in BPH. (b) Positive GOLPH3 expression in LGPIN. (c) Positive GOLPH3 expression in HGPIN. (d) Positive GOLPH3 expression in PC. Original magnification, $\times 400$ (DAB was used as the chromogen and hematoxylin as counterstain).

\section{Immunohistochemical analysis}

The immunohistochemical results were determined by two independent pathologists who were blinded to the clinicopathological data. Tissue sections were stained and AR nuclear expression was assessed by evaluating the proportion and intensity of positively stained carcinoma cells. A score was assigned to represent the estimated percentage of positively stained carcinoma cells, where 0 , none; $1,1 \% ; 2,1-10 \% ; 3$, $10-33 \% ; 4,33-67 \%$; and 5, $\geq 67 \%$. An intensity score was assigned to represent the average estimated stain intensity in positive carcinoma cells, where 0 , none; 1 , weak; 2 , intermediate; and 3 , strong. Proportion and intensity scores were added to obtain a total score ranging from 0 to 8 . Immunohistochemistry results were classified according to the total scores with 0 4 classified as low expression and 5 - 8 as high expression [21].

GOLPH3 expression was determined according to the procedure previously described [11]. Staining for GOLPH3 was considered as positive when cytoplasmic staining was observed in more than $10 \%$ of definite cells. In cases of positive staining, the intensity of stain was recorded as either weak $(1+)$, moderate $(2+)$, or intense $(3+)$. Finally, for immunohistochemistry, results were classified to negative/low expression and moderate/intense expression.

To assess nuclear/cytoplasmic YB-1 expression, YB-1 positive cells were counted. If the proportion of YB-1-positive cells was either less than or greater than $10 \%$, then it was classified either as low or as high expression [21].

\section{Statistical analyses}

Statistical analysis was performed using SPSS16.0 software. Chi-square test and Fischer's exact test were used to investigate the significance of the relationship between GOLPH3, YB-1 and the individual variables. Pearson correlation was used to determine the correlation between each examined antibody and each histopathological entity. The relationship between GOLPH3, YB-1 expression and their clinical outcomes was estimated through both univariate and multivariate analyses. The overall survival (OS) curves were estimated using the Kaplan-Meier method, while the differences in the survival curves were compared using the log-rank test. A multivariate analysis was performed using Cox's regression model. P values $\leq 0.05$ were of statistical significance.

\section{Results}

\section{Clinicopathological data of patients}

The mean age of BPH cases was $65.70 \pm 6.93$ years with a median of 65 years (range 50 - 78 years). For the examined 24 PIN cases, we found the mean age was $66.79 \pm 6.63$ years and a median of 67.50 years (range 50 - 76 years). Twelve cases showed LGPIN and 12 cases HGPIN.

The mean age of PC was $67.68 \pm 6.64$ years with a median 


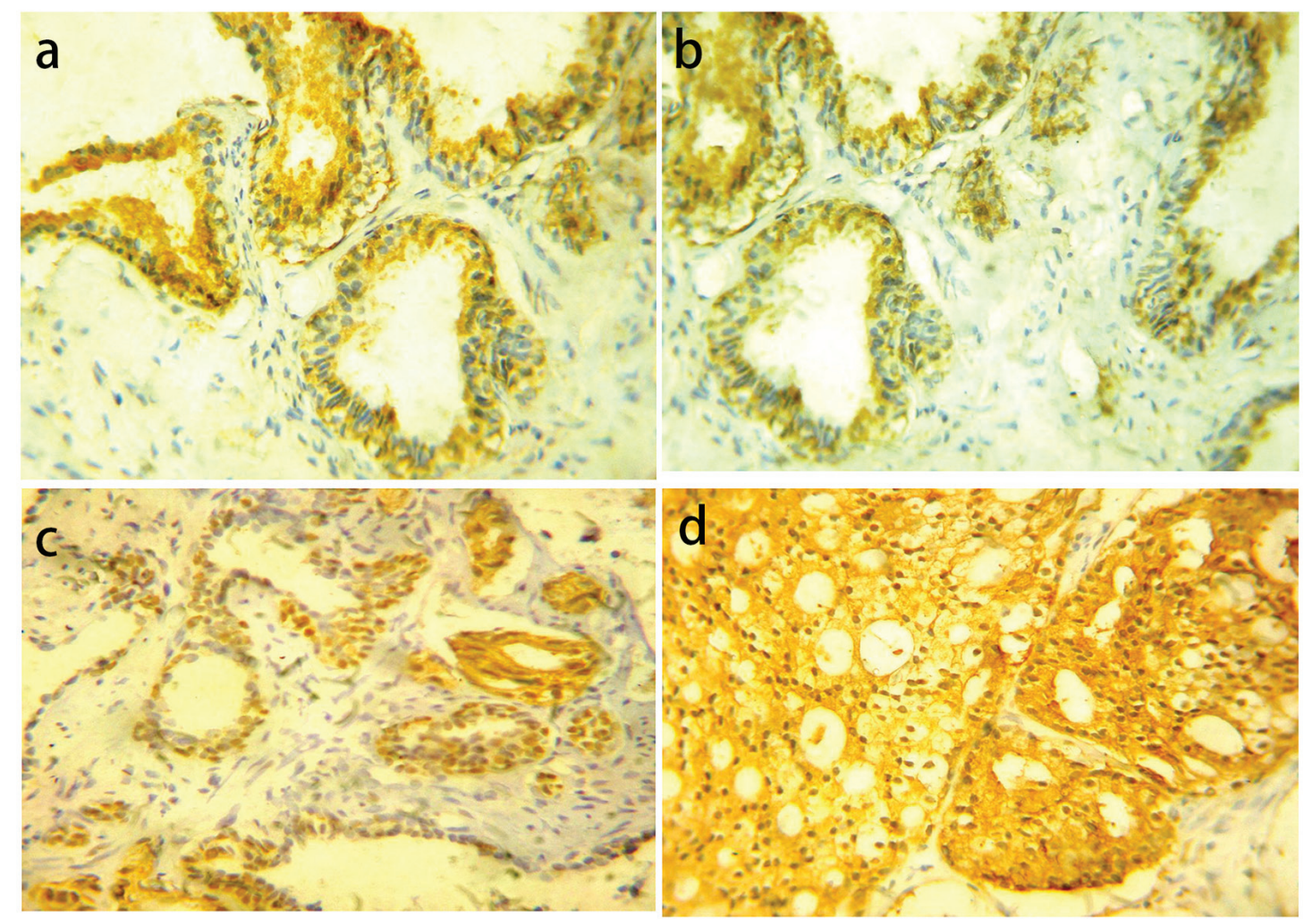

Figure 2. YB-1 protein expression in different prostatic lesions using IHC. (a) YB-1 protein showed cytoplasmic expression in BPH. (b) Positive cytoplasmic YB-1 expression in LGPIN. (c) Positive nuclear and cytoplasmic YB-1 expression in HGPIN. (d) Positive cytoplasmic and nuclear YB-1 expression in PC. Original magnification, $\times 400$ (DAB was used as the chromogen and hematoxylin as counterstain).

of 67.50 years (range 49 - 82 years). Baseline PSA was less than 10 in 13 cases $(17.1 \%)$, between 10 and 20 in 39 cases $(51.3 \%)$ and greater than 20 in 24 cases $(31.6 \%)$. GSs were stratified into Gleason 2 - 6 in 17 cases $(22.4 \%)$, Gleason 7 in 38 cases $(50 \%)$ and Gleason $8-10$ in 21 cases $(27.8 \%)$. Pathological T (pT) stage was classified as pT2 in 40 cases $(52.6 \%)$, pT3 in 27 cases $(35.5 \%)$ and pT4 in nine cases $(11.8 \%)$. Perineural invasion was found in 42 cases $(55.3 \%)$ and absent in 34 cases $(44.7 \%)$. Lymph node metastasis was absent in 61 cases $(80.3 \%)$ and found in 15 cases $(19.7 \%)$. Regarding the stage grouping of cases, five cases $(6.6 \%)$ were stage I, 18 cases $(23.7 \%)$ were stage IIA, 14 cases $(18.4 \%)$ were stage IIB, 21 cases $(27.6 \%)$ were stage III and 18 cases $(23.7 \%)$ were stage IV (Table 1).

\section{GOLPH3 immunohistochemical cytoplasmic expression in the examined groups}

BPH showed negative/weak GOLPH3 expression in $15(75 \%)$ cases and five $(25 \%)$ cases showed moderate/intense expression. PIN cases were negative/weak GOLPH3 expression in 13 $(54.2 \%)$ cases and $11(45.8 \%)$ cases showed moderate/intense expression. LGPIN showed negative/weak GOLPH3 expression in eight $(66.7 \%)$ cases and four $(33.3 \%)$ cases showed moderate expression while HGPIN showed five (41.7\%) nega- tive/weak and seven (58.3\%) moderate/intense expression. There were no statistically significant differences in GOLPH3 expression between LGPIN and HGPIN (P =0.207). As regards carcinoma cases, we found negative/weak GOLPH3 expression in $24(31.6 \%)$ cases and $52(68.4 \%)$ cases showed moderate/intense expression (Fig. 1).

Statistically significant differences were present among GOLPH3 expression in the three previous groups collectively $(\mathrm{P}=0.001)$ and between $\mathrm{BPH}$ vs. $\mathrm{PC}(\mathrm{P}=0.0031)$, PIN vs. carcinoma $(P=0.002)$, while there was no statistically significant difference between BPH vs. PIN ( $\mathrm{P}=0.098)$.

\section{YB-1 immunohistochemical expression}

YB-1 was distributed into both the nucleus and the cytoplasm. For nuclear YB-1 expression, all cases of BPH showed negative expression. PIN cases showed low YB-1 expression in $20(83.3 \%)$ cases and high expression in four (16.7\%) cases. LGPIN showed low YB-1 expression while all high expression cases were HGPIN. There was statistically significant difference in YB-1 expression between LGPIN and HGPIN ( $\mathrm{P}=$ 0.047). Carcinoma cases showed low YB-1 expression in 48 cases $(63.2 \%)$ and high expression in 28 cases $(36.8 \%)$ (Fig. 2).

Statistically significant difference was present among the 
Table 2. Association of GOLPH3 Immunohistochemical Expression With Clinicopathological Parameters in Prostatic Carcinoma $(\mathrm{N}=76)$

\begin{tabular}{|c|c|c|c|}
\hline \multirow{2}{*}{ Clinicopathological parameters } & \multicolumn{2}{|c|}{ Intensity of GOLPH3 expression } & \multirow{2}{*}{ P value } \\
\hline & Negative/low (\%) & Moderate/intense (\%) & \\
\hline Age (years) & & & 0.508 \\
\hline$\leq 60$ & $2(25)$ & $6(75)$ & \\
\hline$>60$ & $22(32.4)$ & $46(67.6)$ & \\
\hline PSA (ng/mL) & & & 0.160 \\
\hline$<10$ & $7(53.8)$ & $6(46.2)$ & \\
\hline $10-20$ & $11(28.2)$ & $28(71.8)$ & \\
\hline$>20$ & $6(25)$ & $18(75)$ & \\
\hline Gleason score & & & 0.034 \\
\hline Gleason 2 - 6 & $6(35.3)$ & $11(64.7)$ & \\
\hline Gleason 7 & $16(42.1)$ & $22(57.9)$ & \\
\hline Gleason 8 - 10 & $2(9.5)$ & $19(90.5)$ & \\
\hline pT status & & & 0.001 \\
\hline $\mathrm{T} 2$ & $20(50)$ & $20(50)$ & \\
\hline $\mathrm{T} 3$ & $3(11.1)$ & $24(88.9)$ & \\
\hline $\mathrm{T} 4$ & $1(11.1)$ & $8(88.9)$ & \\
\hline Perineural invasion & & & 0.085 \\
\hline Absent & $14(41.2)$ & $20(58.8)$ & \\
\hline Present & $10(23.8)$ & $32(76.2)$ & \\
\hline $\mathrm{pN}$ status & & & 0.017 \\
\hline No & $23(37.7)$ & $38(62.3)$ & \\
\hline N1 & $1(6.7)$ & $14(93.3)$ & \\
\hline Stage & & & $<0.001$ \\
\hline I & $4(80)$ & $1(20)$ & \\
\hline IIA & $12(66.7)$ & $6(33.3)$ & \\
\hline IIB & $5(35.7)$ & $9(64.3)$ & \\
\hline III & $2(9.5)$ & $19(90.5)$ & \\
\hline IV & $1(5.6)$ & $17(94.4)$ & \\
\hline AR & & & 0.008 \\
\hline Low expression & $17(45.9)$ & $20(54.1)$ & \\
\hline High expression & $7(17.5)$ & $32(82.1)$ & \\
\hline Mortality & & & $<0.001$ \\
\hline Alive & $22(73.3)$ & $8(26.7)$ & \\
\hline Dead & $2(8.3)$ & $44(84.6)$ & \\
\hline
\end{tabular}

Test of significance: Chi-squared and Fischer's exact tests; $\mathrm{P}<0.05$ is considered significant. pT status: pathological tumor stage; pN: lymph node status; AR: androgen receptor.

examined groups $(\mathrm{P}=0.002)$. However, there was no statistically significant difference between PIN vs. PC $(\mathrm{P}=0.363)$.

For cytoplasmic YB-1 expression, YB-1 expression showed high expression in six cases $(30 \%)$ and low expression in 14 cases $(70 \%)$ of BPH. PIN cases showed high YB-1 expression in 10 cases (41.7) while low expression was found in 14 cases $(58.3 \%)$. There were no statistically significant dif- ferences in YB-1 expression between LGPIN and HGPIN ( $\mathrm{P}=$ $0.660)$. In PC cases YB-1 showed high expression in 48 cases $(63.2 \%)$ and low expression in 28 cases $(36.8 \%)$.

YB-1 cytoplasmic expression was increased from BPH to PIN and from PIN to PC. Statistically significant differences were present among the examined groups $(\mathrm{P}=0.013)$, between $\mathrm{BPH}$ vs. PIN $(\mathrm{P}=0.011)$, PIN vs. $\mathrm{PC}(\mathrm{P}=0.004)$ while there 
Table 3. Association of YB-1 Immunohistochemical Expression With Clinicopathological Parameters in Prostatic Carcinoma $(\mathrm{N}=76)$

\begin{tabular}{|c|c|c|c|c|c|c|}
\hline \multirow{2}{*}{ Clinicopathological parameters } & \multicolumn{3}{|c|}{ Nuclear YB-1 expression } & \multicolumn{3}{|c|}{ Cytoplasmic YB-1 expression } \\
\hline & Low (\%) & High (\%) & P value & Low $(\%)$ & High (\%) & P value \\
\hline Age (years) & & & 0.0129 & & & 0.327 \\
\hline$\leq 60$ & $7(87.7)$ & $1(12.5)$ & & $4(50)$ & $4(50)$ & \\
\hline$>60$ & $41(60.3)$ & $17(39.7)$ & & $24(35.3)$ & $44(64.7)$ & \\
\hline PSA (ng/mL) & & & 0.731 & & & 0.237 \\
\hline$<10$ & $9(69.2)$ & $4(30.8)$ & & $7(53.8)$ & $8(46.2)$ & \\
\hline $10-20$ & $23(59)$ & $16(41)$ & & $14(35.9)$ & $25(64.1)$ & \\
\hline$>20$ & $16(66.7)$ & $8(33.3)$ & & $7(29.2)$ & $17(70.8)$ & \\
\hline Gleason score & & & 0.018 & & & 0.008 \\
\hline Gleason 2 - 6 & $13(76.5)$ & $4(23.5)$ & & $7(41.2)$ & $10(58.8)$ & \\
\hline Gleason 7 & $27(71.1)$ & $11(28.9)$ & & $19(50)$ & $19(50)$ & \\
\hline Gleason $8-10$ & $8(38.1)$ & $13(61.9)$ & & $2(9.5)$ & $19(90.5)$ & \\
\hline pT status & & & 0.428 & & & 0.146 \\
\hline $\mathrm{T} 2$ & $28(70)$ & $12(30)$ & & $18(45)$ & $22(55)$ & \\
\hline $\mathrm{T} 3$ & $15(55.6)$ & $12(44.4)$ & & $9(33.3)$ & $18(66.7)$ & \\
\hline $\mathrm{T} 4$ & $5(55.6)$ & $4(44.4)$ & & $1(11.1)$ & $8(88.9)$ & \\
\hline Perineural invasion & & & 0.073 & & & 0.173 \\
\hline Absent & $25(73.5)$ & $9(26.5)$ & & $15(44.1)$ & $19(55.9)$ & \\
\hline Present & $23(54.8)$ & $19(45.2)$ & & $13(31)$ & $25(69)$ & \\
\hline $\mathrm{pN}$ status & & & 0.277 & & & 0.031 \\
\hline No & $40(65.6)$ & $21(34.4)$ & & $26(42.6)$ & $35(57.4)$ & \\
\hline N1 & $8(53.3)$ & $7(46.7)$ & & $2(13.3)$ & $13(86.7)$ & \\
\hline Stage & & & 0.136 & & & 0.027 \\
\hline I & $5(100)$ & $0(0)$ & & $3(60)$ & $2(40)$ & \\
\hline IIA & $13(72.2)$ & $5(27.8)$ & & $11(61.1)$ & 7 (38.9) & \\
\hline IIB & $10(71.4)$ & $4(28.6)$ & & $5(35.7)$ & $9(64.3)$ & \\
\hline III & $12(57.1)$ & $9(42.9)$ & & $7(33.3)$ & $14(66.7)$ & \\
\hline IV & $8(44.4)$ & $10(55.6)$ & & $2(11.1)$ & $16(88.9)$ & \\
\hline $\mathrm{AR}$ & & & 0.002 & & & $<0.001$ \\
\hline Low expression & $30(81.1)$ & $7(18.9)$ & & $22(59.5)$ & $15(40.5)$ & \\
\hline High expression & $18(46.2)$ & $21(53.8)$ & & $6(15.4)$ & $33(84.6)$ & \\
\hline Mortality & & & 0.107 & & & $<0.001$ \\
\hline Alive & $22(73.3)$ & $8(26.7)$ & & $20(66.7)$ & $10(33.3)$ & \\
\hline Dead & $20(56.5)$ & $20(43.5)$ & & $8(17.4)$ & $38(82.6)$ & \\
\hline
\end{tabular}

Test of significance: Chi-squared and Fischer's exact tests. P < 0.05 is considered significant. pT status: pathological tumor stage; pN: lymph node status; AR: androgen receptor.

was no statistically significant difference between BPH vs. PC $(\mathrm{P}=0.077)$.

\section{Association of GOLPH3 and YB-1 immunohistochemical expression with clinicopathological parameters}

Table 2 summarizes the immunohistochemical results of
GOLPH3 expression in relation to different clinicopathological parameters in PC cases.

Significant positive associations between GOLPH3 moderate/intense expression and Gleason score, pathological $\mathrm{T}$ (pT) stage, LNM ( $\mathrm{pN}$ status) and stage were identified $(\mathrm{P}=$ $0.034, \mathrm{P}=0.001, \mathrm{P}=0.017$ and $\mathrm{P}<0.001$ respectively). There was a positive association between GOLPH3 moderate/intense expression and AR $(\mathrm{P}=0.008)$. No significant associations 
Table 4. Correlations Between Immunohistochemical Markers in Different Lesions

\begin{tabular}{|c|c|c|c|c|c|}
\hline Lesion & Marker expression & & GOLPH3 & Nuclear YB-1 & Cytoplasmic YB-1 \\
\hline \multirow[t]{6}{*}{ BPH } & \multirow[t]{2}{*}{ GOLPH3 } & Pearson correlation & - & 0.103 & $0.649^{*}$ \\
\hline & & Sig. (two-tailed) & - & 0.665 & 0.002 \\
\hline & \multirow[t]{2}{*}{ Nuclear YB-1 } & Pearson correlation & 0.103 & - & 0.116 \\
\hline & & Sig. (two-tailed) & 0.665 & - & 0.627 \\
\hline & \multirow[t]{2}{*}{ Cytoplasmic YB-1 } & Pearson correlation & $0.649^{*}$ & 0.116 & - \\
\hline & & Sig. (two-tailed) & 0.002 & 0.627 & - \\
\hline \multirow[t]{6}{*}{ PIN } & \multirow[t]{2}{*}{ GOLPH3 } & Pearson correlation & - & $0.922 * *$ & 0.399 \\
\hline & & Sig. (two-tailed) & - & $<0.001$ & 0.101 \\
\hline & \multirow[t]{2}{*}{ Nuclear YB-1 } & Pearson correlation & $0.922 * *$ & - & $0.559^{*}$ \\
\hline & & Sig. (two-tailed) & $<0.001$ & - & 0.016 \\
\hline & \multirow[t]{2}{*}{ Cytoplasmic YB-1 } & Pearson correlation & 0.399 & $0.559^{*}$ & - \\
\hline & & Sig. (two-tailed) & 0.101 & 0.016 & - \\
\hline \multirow[t]{6}{*}{ Carcinoma } & \multirow[t]{2}{*}{ GOLPH3 } & Pearson correlation & - & $0.777 * *$ & $0.438 * *$ \\
\hline & & Sig. (two-tailed) & - & $<0.001$ & $<0.001$ \\
\hline & \multirow[t]{2}{*}{ Nuclear YB-1 } & Pearson correlation & $0.777 * *$ & - & $0.611^{* *}$ \\
\hline & & Sig. (two-tailed) & $<0.001$ & - & $<0.001$ \\
\hline & \multirow[t]{2}{*}{ Cytoplasmic YB-1 } & Pearson correlation & $0.438 * *$ & $0.611 * *$ & - \\
\hline & & Sig. (two-tailed) & $<0.001$ & $<0.001$ & - \\
\hline
\end{tabular}

Test of significance: Pearson correlation. ${ }^{* *}$ Correlation is significant at the 0.01 level (two-tailed). ${ }^{*}$ Correlation is significant at the 0.05 level (two-tailed).

were seen in relation to patients' age, PAS level and perineural invasion. YB-1 nuclear and cytoplasmic expression in relation to different clinicopathological parameters in PC cases was summarized in Table 3.

There were positive associations between nuclear YB-1 expression and Gleason score and $\mathrm{AR}(\mathrm{P}=0.018$ and $\mathrm{P}=0.024$ respectively). No significant associations were seen with other clinicopathological parameters. Cytoplasmic YB-1 expression was associated with Gleason score, LNM ( $\mathrm{pN}$ status), stage and AR $(\mathrm{P}=0.008, \mathrm{P}=0.031, \mathrm{P}=0.027$ and $\mathrm{P}<0.001$ respectively). No significant associations were seen with other clinicopathological parameters.

\section{Correlations between immunohistochemical markers in different examined lesions}

Correlations between immunohistochemical markers in different examined lesions are shown in Table 4.

In $\mathrm{BPH}$ cases, a significant positive correlation was noted between GOLPH3/cytoplasmic YB-1 expression ( $\mathrm{r}=0.649$, $\mathrm{P}=0.002)$. No significant correlation was noted between GOLPH3/nuclear YB-1 expression $(r=0.103, \mathrm{P}=0.665)$ and between nuclear/cytoplasmic YB-1 expression $(\mathrm{r}=0.116, \mathrm{P}=$ 0.627).

In PIN cases, a significant positive correlation was noted between GOLPH3/nuclear YB-1 expression ( $\mathrm{r}=0.922, \mathrm{P}<$ $0.001)$ and between nuclear/cytoplasmic YB-1 expression $(r$
$=0.559, \mathrm{P}=0.016)$ while no significant correlation was noted between GOLPH3/cytoplasmic YB-1 expression ( $\mathrm{r}=0.399, \mathrm{P}$ $=0.101)$.

In PC cases, a significant positive correlation was noted between GOLPH3/nuclear and cytoplasmic YB-1 expression ( $\mathrm{r}=0.777, \mathrm{P}<0.001$ and $\mathrm{r}=0.438, \mathrm{P}<0.001$ respectively $)$ and between nuclear/cytoplasmic YB-1 expression ( $\mathrm{r}=0.611$, $\mathrm{P}<0.001)$.

\section{Prognostic value and survival analysis}

The time of OS ranged from 4 to 60 months with a mean \pm standard deviation (SD) of $26.20 \pm 15.634$ months and a median survival time of 21 months. The OS was $39.5 \%$.

High Gleason score $(\mathrm{P}=0.004), \mathrm{pT}$ status $(\mathrm{P}<0.001), \mathrm{pN}$ status $(\mathrm{P}<0.001)$, high stage $(\mathrm{P}<0.001)$ and AR $(\mathrm{P}=0.006)$ were the only adverse prognostic clinicopathological factors. While OS rate was not significantly influenced by patients' age $(\mathrm{P}=0.896)$, PSA $(\mathrm{P}=0.128)$, and perineural invasion $(\mathrm{P}=$ 0.064). Compared to patients with moderate/intense GOLPH3 expression, the patients whose tumor cells showed weak expression of GOLPH3 had significantly better outcomes in OS $(\mathrm{P}<0.001)$. As regards nuclear and cytoplasmic YB-1 expression, we found that high YB-1 expression was associated with shorter OS and weak expression associated with better OS (P $=0.020$ and $\mathrm{P}<0.001$ respectively) (Fig. 3).

In the multivariate analysis, moderate/intense GOLPH3 
a

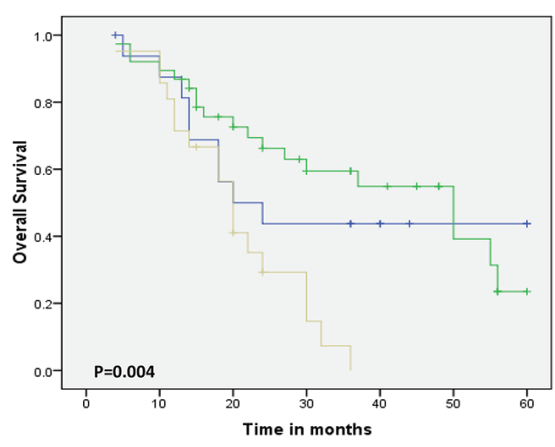

C

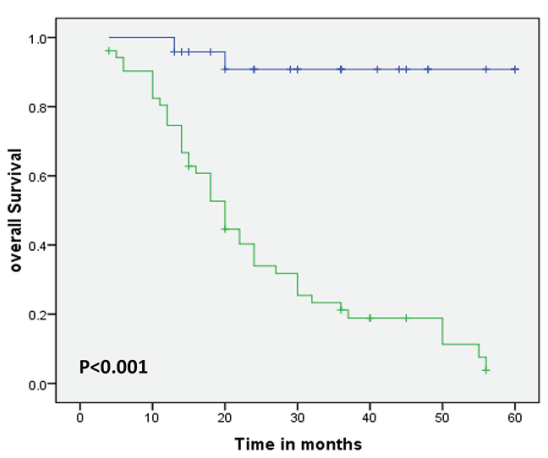

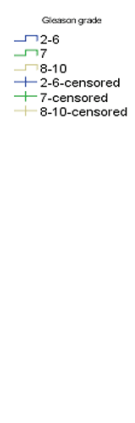

b s survival functions

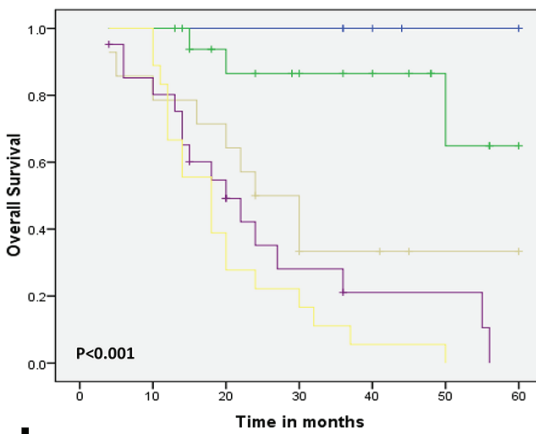

d

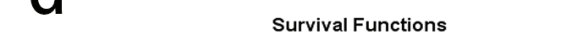

Survival Functions

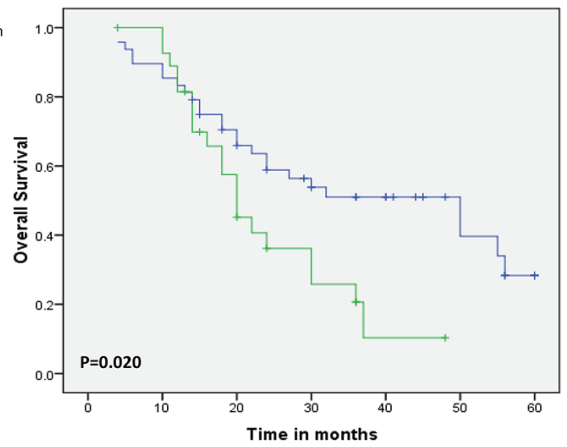

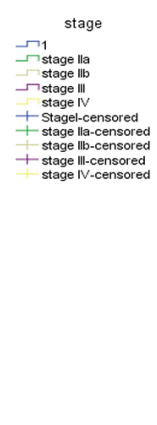
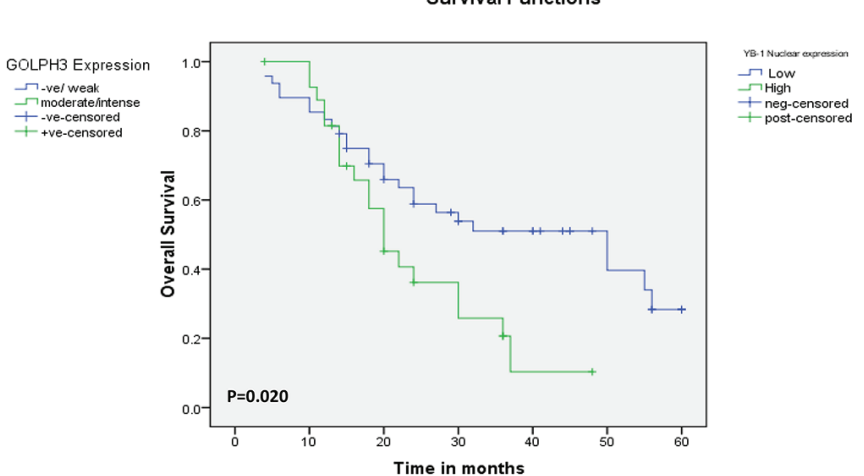

\section{e Survival Functions}
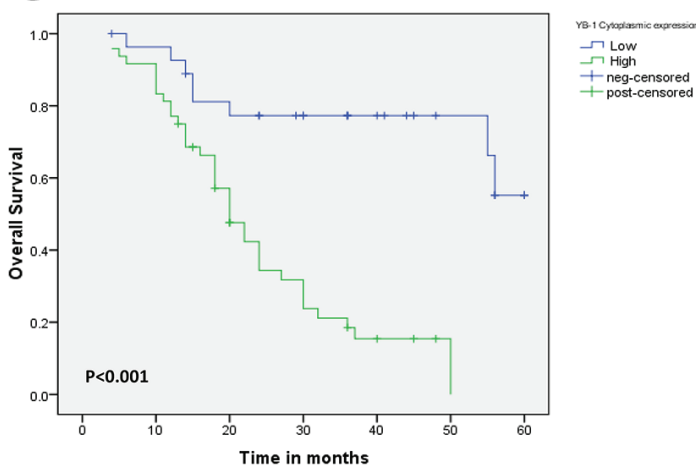

Figure 3. (a-e) Kaplan-Meier plots for overall survival in PC patients according to Gleason grade (a) and tumor stage (b), GOLPH3 expression (c), nuclear YB-1 (d) and cytoplasmic YB-1 expression (e) with significant P values using log-rank test.

expression continued to be a significant predictor of $\mathrm{OS}(\mathrm{P}=$ 0.025 , Table 5).

\section{Discussion}

$\mathrm{PC}$ is a serious disease that represents different challenges to the urologists, pathologists and oncologists [22]. Treatment of PC includes either surgical castration or androgen ablation therapy with transition from hormone refractory stage to metastatic stage during treatment [23]. The ordinary prognostic factors for PC include Gleason score, PSA and clinical stage. However, these factors seem to be inadequate to determine the possibility of recurrence or metastasis [24]. Therefore, reliable biomarkers have to be studied.

Recent studies have implicated GOLPH3 and YB-1 in integrin-mediated cell migration and invasion in glioma and breast cancer cells $[9,15,25]$. In glioma cells, the function of GOLPH3 requires $\mathrm{mTOR}$ and its effector YB-1. Upregulation of GOLPH3 is accompanied by increased activity of mTOR and YB-1. Both treatment with the mTOR inhibitor INK128 and YB-1 knockdown decrease the migration and invasiveness 
Table 5. Multivariate Analyses of Overall Survival in Prostate Carcinoma Patients

\begin{tabular}{llll} 
Variables & HR & $\mathbf{9 5 \%}$ CI & P value \\
\hline Grade & 0.840 & $0.518-1.361$ & 0.478 \\
pT status & 0.923 & $0.507-1.679$ & 0.792 \\
pN status & 0.997 & $0.359-2.515$ & 0.994 \\
Stage & 1.574 & $0.939-2.637$ & 0.085 \\
AR & 1.086 & $0.603-2.451$ & 0.585 \\
GOLPH3 & 5.970 & $1.252-28.459$ & 0.025 \\
Nuclear YB-1 & 1.216 & $0.603-2.451$ & 0.585 \\
Cytoplasmic YB-1 & 2.100 & $0.731-6.036$ & 0.168 \\
\hline
\end{tabular}

Test of significance: Cox regression analysis. $\mathrm{P}<0.05$ is considered significant. HR: hazard ratio; $\mathrm{Cl}$ : confidence interval.

of glioma cells in vitro [15]. In non-invasive breast epithelial cells, YB-1 was shown to promote the epithelial-mesenchymal transition [26]. The invasion capacity of breast cancer cells depends on GOPLPH3 interaction with phosphatidylinositol 4-phosphate [27].

In the current study, moderate/intense cytoplasmic expression of GOLPH3 protein was found in $25 \%$ of $\mathrm{BPH}$ and in $68.4 \%$ of PC tissues and the difference was statistically significant. This result was similar to a previous study that reported $30 \%$ positivity in BPH and $64 \%$ in PC samples [28] but higher than previous studies that detected moderate/intense GOLPH3 expression in $5 \%$ of BPH, $8 \%$ of HGPIN and $37-40.66 \%$ of $\mathrm{PC}[8,11]$. Therefore, differences noted in the expression of GOLPH3 in PC compared with BPH and PIN may facilitate the clinical diagnoses of PC. Similar to a previous study in castration-resistant PC, GOLPH3 expression was positively correlated with Gleason score, tumor stage and lymph node metastasis [11]. On the contrary, no significant associations were found with Gleason score or tumor stage [28]. Collectively, these observations suggest that GOLPH3 acts as an oncogene in PC and may be a useful target for therapeutic interventions $[11,28,29]$. This result is supported by detection of GOLPH3 amplification in lung cancer [29]. Similarly, GOLPH3 has been considered as a novel oncogene involved in the development of cancer of the lung, ovary, breast, colon and prostate, as well as melanoma, rhabdomyosarcoma, and glioma [8, 30-32]. Emerging evidence has indicated that GOLPH3 was an androgen-regulated gene. In the present study, GOLPH3 expression was significantly associated with AR expression. This result was confirmed by another study that suggested that GOLPH3 upregulation may be involved in the progression from androgen-dependent to androgen-independent growth [28].

Previous studies in PC have shown that YB-1 played a role in enhancing cell proliferation, resistance to castration [21] and drug resistance [33]. Accordingly, therapy targeting YB-1 using adenovirus vector [34] and decoy peptide [35] can lead to suppression of PC proliferation.

In the present study, YB-1 was primarily expressed in the cytoplasm of benign prostate tissue at a low level and begins to increase with progression into malignant tissue. Following malignant transformation, YB-1 expression started to appear in the nuclei of both HGPIN and PC and this result was statistically significant despite of the little bit difficulty found during distinguishing nuclear from cytoplasmic staining. This finding was confirmed by other studies in prostate [36, 37]. Many studies have shown elevated YB-1 protein levels in malignant tissues compared with normal tissues, and higher levels of YB-1 have also been associated with higher tumor grade and poorer patient prognosis in different malignancies, including breast [38, 39], lung [40] and ovarian cancers [41]. Subsequently, YB-1 activities regarding oncogenic properties, cell proliferation and drug resistance are related to its nuclear translocation accompanied by altered gene transcription and chromosomal instability [21, 37].

Both high nuclear and cytoplasmic YB-1 expression was correlated with Gleason score as well as with AR expression in agreement with previous studies [33, 37-39]. On the contrary, high nuclear YB-1 expression was not correlated with Gleason score but correlated with advanced tumor stage [17]. In our study, only cytoplasmic expression was correlated with advanced stage. Many studies found that AR was a direct gene target of YB-1 and YB-1 was found to regulate AR transcription via binding to the AR promoter $[21,42]$. In PC, YB-1 high expression converted androgen-dependent cells into castration-resistant cells. Thus, therapeutic targeting of YB-1 may be applicable in cases with AR splice variants in castrationresistant PC [21].

A significant positive correlation was noted between GOLPH3/nuclear and cytoplasmic YB-1 expression in PC cases of the present study. This finding was also reported in glioma cancer cells which demonstrated that overexpression of GOLPH3 increased the protein level of YB-1 and GOLPH3 up-regulation is accompanied by an increase of YB-1 level and mTOR activity, suggesting that GOLPH3 is located at the upstream of YB-1. The effect of GOLPH3 on enhancing migration and invasion of glioma cells could be abolished by either treatment with the mTOR inhibitor INK128 or by YB-1 knockdown [15].

In the current study like a previous study, high Gleason grade, advanced tumor stage, and AR were associated with shorter OS [11]. GOLPH3 positive expression was also associated with shorter OS. Therefore, the level of GOLPH3 expression in radical prostatectomy samples may be useful for predicting OS and can be an important parameter for the prognosis of PC patients. Previous studies have indicated that high level of GOLPH3 expression promotes tumorigenesis and progression of several types of malignancies including PC and was associated with poor prognosis [10, 14, 15, 25, 43]. Similarly, high nuclear and cytoplasmic YB-1 expression was associated with shorter OS. So, YB-1 overexpression can be regarded as a sign of poor prognosis and can be used as biomarker for tumor aggressiveness as reported in previous studies on PC, breast cancer, ovarian cancer and lung cancer [39-41, 44]. Both GOLPH3 and YB-1 enhance cell mortality. On the other hand, multivariate analysis indicated that GOLPH3 was the only significant prognostic factor of OS in all PC patients and this finding was also reported by another study [11]. On the contrary, neither nuclear nor cytoplasmic YB-1 expression was not associated with OS and it can be considered as independent 
prognostic factor. Therefore, GOLPH3 positive expression can be superior over YB-1 high expression as a poor prognostic marker for $\mathrm{PC}$ patients.

In conclusion, GOLPH3, nuclear/cytoplasmic YB-1 expression correlated with the Gleason score, AR expression and poor OS in PC tissues. Both markers work in the same molecular pathway and function as oncogenes. Based on these findings, we revealed that both GOLPH 3 and YB-1 may be promising molecular targets for new therapeutic cancer strategies during the treatment of both androgen-dependent PC and castration-resistant PC.

\section{Clinical practice points}

$\mathrm{PC}$ is an aggressive disease. Despite advances in the treatment, the mechanisms involved in progression and recurrence are still unclear. New prognostic markers should be explored for better design of therapeutic regimens. The role of GOLPH3 and YB-1 is still under research in PC. Immunohistochemical analysis of GOLPH3 and YB-1 in different lesions of the prostate that included 20 benign prostatic hyperplasia (BPH), 20 prostatic intraepithelial neoplasia (PIN) and 67 PC cases was done.

Moderate/intense cytoplasmic expression GOLPH3 expression was found in $25 \%$ of BPH cases, $45.8 \%$ of PIN cases and in $68.4 \%$ of PC cases. Regarding nuclear YB-1, all cases of BPH showed negative expression. High expression was detected in $16.7 \%$ of PIN cases and in $36.8 \%$ of PC cases. For cytoplasmic YB-1 expression, high expression was found in $30 \%$ of BPH cases, $41.7 \%$ of PIN cases and in $63.2 \%$ of PC cases.

Significant positive associations between GOLPH3 expression, YB-1, Gleason score, stage and AR were found. In PC cases, a significant positive correlation was noted between GOLPH3/nuclear and cytoplasmic YB-1 expression.

High Gleason score, high stage, AR, high GOLPH3, and high nuclear/cytoplasmic YB-1 expression were the only adverse prognostic factors. In the multivariate analysis, GOLPH3 expression continued to be a significant predictor of OS. Both markers can be promising targets for new treatment strategies.

\section{Competing Interests}

The authors declare that they have no competing interests.

\section{References}

1. Niu Z, Guohua R, Shuping S. Diagnosis and treatment for prostate cancer. Chinese-German. J Clin Oncol. 2008; 7:492-494.

2. Ibrahim AS, Khaled HM, Mikhail NN, Baraka H, Kamel H. Cancer incidence in egypt: results of the national population-based cancer registry program. J Cancer Epidemiol. 2014;2014:437971.

3. MacVicar GR, Hussain MH. Emerging therapies in metastatic castration-sensitive and castration-resistant prostate cancer. Curr Opin Oncol. 2013;25(3):252-260.
4. Klink JC, Miocinovic R, Magi Galluzzi C, Klein EA. High-grade prostatic intraepithelial neoplasia. Korean J Urol. 2012;53(5):297-303.

5. Epstein JI, Herawi M. Prostate needle biopsies containing prostatic intraepithelial neoplasia or atypical foci suspicious for carcinoma: implications for patient care. J Urol. 2006;175(3 Pt 1):820-834.

6. Poelaert F, Van Praet C, Beerens AS, De Meerleer G, Fonteyne V, Ost P, Lumen N. The role of androgen receptor expression in the curative treatment of prostate cancer with radiotherapy: a pilot study. Biomed Res Int. 2015;2015:812815.

7. Wood CS, Schmitz KR, Bessman NJ, Setty TG, Ferguson KM, Burd CG. PtdIns4P recognition by Vps74/GOLPH3 links PtdIns 4-kinase signaling to retrograde Golgi trafficking. J Cell Biol. 2009;187(7):967-975.

8. Scott KL, Kabbarah O, Liang MC, Ivanova E, Anagnostou V, Wu J, Dhakal S, et al. GOLPH3 modulates mTOR signalling and rapamycin sensitivity in cancer. Nature. 2009;459(7250):1085-1090.

9. Tokuda E, Itoh T, Hasegawa J, Ijuin T, Takeuchi Y, Irino Y, Fukumoto M, et al. Phosphatidylinositol 4-phosphate in the Golgi apparatus regulates cell-cell adhesion and invasive cell migration in human breast cancer. Cancer Res. 2014;74(11):3054-3066.

10. Li H, Guo L, Chen SW, Zhao XH, Zhuang SM, Wang LP, Song LB, et al. GOLPH3 overexpression correlates with tumor progression and poor prognosis in patients with clinically N0 oral tongue cancer. J Transl Med. 2012;10:168.

11. Hua X, Yu L, Pan W, Huang X, Liao Z, Xian Q, Fang L, et al. Increased expression of Golgi phosphoprotein-3 is associated with tumor aggressiveness and poor prognosis of prostate cancer. Diagn Pathol. 2012;7:127.

12. Xue Y, Wu G, Liao Y, Xiao G, Ma X, Zou X, Zhang G, et al. GOLPH3 is a novel marker of poor prognosis and a potential therapeutic target in human renal cell carcinoma. Br J Cancer. 2014;110(9):2250-2260.

13. Dai T, Zhang D, Cai M, Wang C, Wu Z, Ying Z, Wu J, et al. Golgi phosphoprotein 3 (GOLPH3) promotes hepatocellular carcinoma cell aggressiveness by activating the NF-kappaB pathway. J Pathol. 2015;235(3):490-501.

14. $\mathrm{Hu} \mathrm{BS}, \mathrm{Hu} \mathrm{H}$, Zhu CY, Gu YL, Li JP. Overexpression of GOLPH3 is associated with poor clinical outcome in gastric cancer. Tumour Biol. 2013;34(1):515-520.

15. Zhang X, Ding Z, Mo J, Sang B, Shi Q, Hu J, Xie S, et al. GOLPH3 promotes glioblastoma cell migration and invasion via the mTOR-YB1 pathway in vitro. Mol Carcinog. 2015;54(11):1252-1263.

16. Kohno K, Izumi H, Uchiumi T, Ashizuka M, Kuwano M. The pleiotropic functions of the Y-box-binding protein, YB-1. Bioessays. 2003;25(7):691-698.

17. Imada K, Shiota M, Kohashi K, Kuroiwa K, Song Y, Sugimoto M, Naito S, et al. Mutual regulation between Raf/MEK/ERK signaling and Y-box-binding protein-1 promotes prostate cancer progression. Clin Cancer Res. 2013;19(17):4638-4650.

18. Kuwano M, Uchiumi T, Hayakawa H, Ono M, Wada M, Izumi $\mathrm{H}$, Kohno $\mathrm{K}$. The basic and clinical implications 
of $\mathrm{ABC}$ transporters, Y-box-binding protein-1 (YB-1) and angiogenesis-related factors in human malignancies. Cancer Sci. 2003;94(1):9-14.

19. To K, Fotovati A, Reipas KM, Law JH, Hu K, Wang J, Astanehe A, et al. Y-box binding protein-1 induces the expression of CD44 and CD49f leading to enhanced selfrenewal, mammosphere growth, and drug resistance. Cancer Res. 2010;70(7):2840-2851.

20. Gluz O, Mengele K, Schmitt M, Kates R, Diallo-Danebrock R, Neff F, Royer HD, et al. Y-box-binding protein YB-1 identifies high-risk patients with primary breast cancer benefiting from rapidly cycled tandem high-dose adjuvant chemotherapy. J Clin Oncol. 2009;27(36):61446151.

21. Shiota M, Takeuchi A, Song Y, Yokomizo A, Kashiwagi E, Uchiumi T, Kuroiwa K, et al. Y-box binding protein-1 promotes castration-resistant prostate cancer growth via androgen receptor expression. Endocr Relat Cancer. 2011;18(4):505-517.

22. Jemal A, Bray F, Center MM, Ferlay J, Ward E, Forman D. Global cancer statistics. CA Cancer J Clin. 2011;61(2):69-90.

23. Wedel S, Hudak L, Seibel JM, Makarevic J, Juengel E, Tsaur I, Waaga-Gasser A, et al. Molecular targeting of prostate cancer cells by a triple drug combination downregulates integrin driven adhesion processes, delays cell cycle progression and interferes with the cdk-cyclin axis. BMC Cancer. 2011;11:375.

24. Moussa AS, Li J, Soriano M, Klein EA, Dong F, Jones JS. Prostate biopsy clinical and pathological variables that predict significant grading changes in patients with intermediate and high grade prostate cancer. BJU Int. 2009;103(1):43-48.

25. Zhou X, Zhan W, Bian W, Hua L, Shi Q, Xie S, Yang D, et al. GOLPH3 regulates the migration and invasion of glioma cells though RhoA. Biochem Biophys Res Commun. 2013;433(3):338-344.

26. Evdokimova V, Tognon C, Ng T, Ruzanov P, Melnyk N, Fink D, Sorokin A, et al. Translational activation of snaill and other developmentally regulated transcription factors by YB-1 promotes an epithelial-mesenchymal transition. Cancer Cell. 2009;15(5):402-415.

27. Sechi S, Colotti G, Belloni G, Mattei V, Frappaolo A, Raffa GD, Fuller MT, et al. GOLPH3 is essential for contractile ring formation and Rab11 localization to the cleavage site during cytokinesis in Drosophila melanogaster. PLoS Genet. 2014;10(5):e1004305.

28. Li W, Guo F, Gu M, Wang G, He X, Zhou J, Peng Y, et al. Increased Expression of GOLPH3 is Associated with the Proliferation of Prostate Cancer. J Cancer. 2015;6(5):420429.

29. Scott KL, Chin L. Signaling from the Golgi: mechanisms and models for Golgi phosphoprotein 3-mediated oncogenesis. Clin Cancer Res. 2010;16(8):2229-2234.

30. Kunigou O, Nagao H, Kawabata N, Ishidou Y, Nagano S, Maeda S, Komiya S, et al. Role of GOLPH3 and GOLPH3L in the proliferation of human rhabdomyosarcoma. Oncol Rep. 2011;26(5):1337-1342.

31. Li XY, Liu W, Chen SF, Zhang LQ, Li XG, Wang LX.
Expression of the Golgi phosphoprotein-3 gene in human gliomas: a pilot study. J Neurooncol. 2011;105(2):159163.

32. Romanuik TL, Wang G, Holt RA, Jones SJ, Marra MA, Sadar MD. Identification of novel androgen-responsive genes by sequencing of LongSAGE libraries. BMC Genomics. 2009;10:476.

33. Shiota M, Izumi H, Tanimoto A, Takahashi M, Miyamoto N, Kashiwagi E, Kidani A, et al. Programmed cell death protein 4 down-regulates Y-box binding protein-1 expression via a direct interaction with Twist1 to suppress cancer cell growth. Cancer Res. 2009;69(7):3148-3156.

34. Glockzin G, Mantwill K, Jurchott K, Bernshausen A, Ladhoff A, Royer HD, Gansbacher B, et al. Characterization of the recombinant adenovirus vector AdYB-1: implications for oncolytic vector development. J Virol. 2006;80(8):3904-3911.

35. Law JH, Li Y, To K, Wang M, Astanehe A, Lambie K, Dhillon J, et al. Molecular decoy to the Y-box binding protein-1 suppresses the growth of breast and prostate cancer cells whilst sparing normal cell viability. PLoS One. 2010;5(9).

36. Gimenez-Bonafe P, Fedoruk MN, Whitmore TG, Akbari M, Ralph JL, Ettinger S, Gleave ME, et al. YB-1 is upregulated during prostate cancer tumor progression and increases P-glycoprotein activity. Prostate. 2004;59(3):337349.

37. Khan MI, Adhami VM, Lall RK, Sechi M, Joshi DC, Haidar OM, Syed DN, et al. YB-1 expression promotes epithelial-to-mesenchymal transition in prostate cancer that is inhibited by a small molecule fisetin. Oncotarget. 2014;5(9):2462-2474.

38. Habibi G, Leung S, Law JH, Gelmon K, Masoudi H, Turbin D, Pollak M, et al. Redefining prognostic factors for breast cancer: YB-1 is a stronger predictor of relapse and disease-specific survival than estrogen receptor or HER-2 across all tumor subtypes. Breast Cancer Res. 2008;10(5):R86.

39. Dahl E, En-Nia A, Wiesmann F, Krings R, Djudjaj S, Breuer E, Fuchs T, et al. Nuclear detection of Y-box protein-1 (YB-1) closely associates with progesterone receptor negativity and is a strong adverse survival factor in human breast cancer. BMC Cancer. 2009;9:410.

40. Panupinthu N, Yu S, Zhang D, Zhang F, Gagea M, Lu Y, Grandis JR, et al. Self-reinforcing loop of amphiregulin and Y-box binding protein-1 contributes to poor outcomes in ovarian cancer. Oncogene. 2014;33(22):2846-2856.

41. Rybalkina E, Stromskaia TP, Ovchinnikov LP, Stavrovskaia AA. [Connection of intracellular protein YB-1 localization in cell cultures of human tumors with multidrug resistance]. Vopr Onkol. 2013;59(5):623-628.

42. Finkbeiner MR, Astanehe A, To K, Fotovati A, Davies $\mathrm{AH}$, Zhao Y, Jiang H, et al. Profiling YB-1 target genes uncovers a new mechanism for MET receptor regulation in normal and malignant human mammary cells. Oncogene. 2009;28(11):1421-1431.

43. Wang Z, Jiang B, Chen L, Di J, Cui M, Liu M, Ma Y, et al. GOLPH3 predicts survival of colorectal cancer patients treated with 5-fluorouracil-based adjuvant chemotherapy. 
J Transl Med. 2014;12:15.

44. Shibahara K, Sugio K, Osaki T, Uchiumi T, Maehara Y, Kohno K, Yasumoto K, et al. Nuclear expression of the Y- box binding protein, YB-1, as a novel marker of disease progression in non-small cell lung cancer. Clin Cancer Res. 2001;7(10):3151-3155. 